\title{
Sustained-Release Erythropoietin Ameliorates Cardiac Function in Infarcted Rat-Heart Without Inducing Polycythemia
}

\author{
Xue Lin, MD; Masatoshi Fujita, MD*; Naoki Kanemitsu, MD; Yu Kimura, MD**; \\ Keiichi Tambara, MD; Goditha U. Premaratne, MD; Atsushi Nagasawa, MD; \\ Tadashi Ikeda, MD; Yasuhiko Tabata, PhD**; Masashi Komeda, MD
}

\begin{abstract}
Background The usefulness of sustained-release erythropoietin for improving left ventricular (LV) function without polycythemia was evaluated in a rat chronic myocardial infarction model.

Methods and Results Four weeks after left coronary artery ligation, 50 Sprague-Dawley rats were assigned to 5 groups $(n=10$, each). Control group had a gelatin sheet $(20 \times 20 \mathrm{~mm})$ containing saline applied to the infarct area, whereas the 4 treatment groups had gelatin sheets incorporating erythropoietin $0.1 \mathrm{U}, 1 \mathrm{U}, 10 \mathrm{U}$ and $100 \mathrm{U}$, respectively. Endpoint measurements performed at 8 weeks after the coronary ligation revealed that the fractional area change was larger for erythropoietin $1 \mathrm{U}$ and $10 \mathrm{U}$ than in the other 3 groups. The $\mathrm{LV}$ end-systolic elastance and the time constant of isovolumic relaxation were better for erythropoietin $1 \mathrm{U}$ and $10 \mathrm{U}$ than in the other 3 groups. The density of vessels larger than $50 \mu \mathrm{m}$ in diameter was the highest in the erythropoietin $1 \mathrm{U}$ group. The number of red blood cells was significantly increased in groups receiving erythropoietin $10 \mathrm{U}$ and $100 \mathrm{U}$.

Conclusions Gelatin hydrogel sheets incorporating $1 \mathrm{U}$ erythropoietin improved LV function without inducing polycythemia in a rat chronic myocardial infarction model. (Circ J 2007; 71: 132-137)

Key Words: Angiogenesis; Chronic myocardial infarction; Erythropoietin; Sustained-release; Ventricular remodeling
\end{abstract}

$\mathbf{R}$ ecent advances in coronary reperfusion strategies and pharmacological management have resulted in an increasing number of survivors of acute myocardial infarction (AMI) who have a higher risk of developing left ventricular (LV) remodeling and chronic heart failure. Although therapeutic approaches aimed at delivering blood flow to the myocardium at risk are needed to improve cardiac function and prevent progression of LV remodeling, some patients have no revascularization options because of the diffuse nature of their coronary artery lesions. In such patients, therapeutic angiogenesis is being explored as an alternative strategy for providing significant blood flow to the akinetic myocardial tissue. Although initial uncontrolled clinical studies of therapeutic angiogenesis have generated a great deal of hope, the effectiveness of angiogenic growth factor has not been confirmed by subsequent randomized trials! 1,2

As a result, delivery strategies to achieve clinically significant angiogenic responses with sustained-release (SR) angiogenic growth factors are being explored $3^{3-5}$ Recently, we developed a biodegradable gelatin hydrogel sheet incorporating basic fibroblast growth factor (bFGF), which

(Received August 1, 2006; revised manuscript received September 19, 2006; accepted October 13, 2006)

Department of Cardiovascular Surgery, Graduate School of Medicine, *School of Health Sciences, Faculty of Medicine and **Department of Biomaterials, Field of Tissue Engineering, Institute for Frontier Medical Sciences, Kyoto University, Kyoto, Japan

Mailing address: Masashi Komeda, MD, Professor and Chairman, Department of Cardiovascular Surgery, Graduate School of Medicine, Kyoto University, 54 Kawahara-cho, Shogoin, Sakyo-ku, Kyoto 6068507, Japan. E-mail: komelab@kuhp.kyoto-u.ac.jp enabled the bFGF to be released at the site of action for a sufficient time period 6,7

Several recent studies have demonstrated that erythropoietin (EPO) has protective effects against ischemic injury in the brain, spinal cord, retina, ${ }^{10,11}$ kidney, ${ }^{12}$ and most recently, in the myocardium ${ }^{13-17}$ EPO treatment has been reported to improve cardiac function in a post-infarction heart failure model ${ }^{18-20}$ However, systemic treatment with a large dose of EPO is accompanied by polycythemia as an endogenous function of EPO, which may predispose to thromboembolic complications! ${ }^{15,18}$

Thus, in the present study, we aimed to develop a biodegradable gelatin hydrogel sheet incorporating EPO and to determine the appropriate dose of EPO for improving LV function without inducing polycythemia in a rat chronic myocardial infarction (MI) model.

\section{Methods}

Male Sprague-Dawley rats were used in this study. All experimental procedures were performed in accordance with the guidelines for Animal Experiments of Kyoto University, which conforms to the law of "Guide for the Care and Use of Laboratory Animals" in Japan and conforms to the "Guide for the Care and Use of Laboratory Animals" published by the US National Institutes of Health (NIH Publication No. 85-23, revised 1996).

Preparation of Gelatin Hydrogel Sheets Incorporating EPO Gelatin was prepared through an acid process of pig skin type I collagen and kindly supplied by Nitta Gelatin, Osaka, Japan. Gelatin hydrogel sheets were made using the pre- 


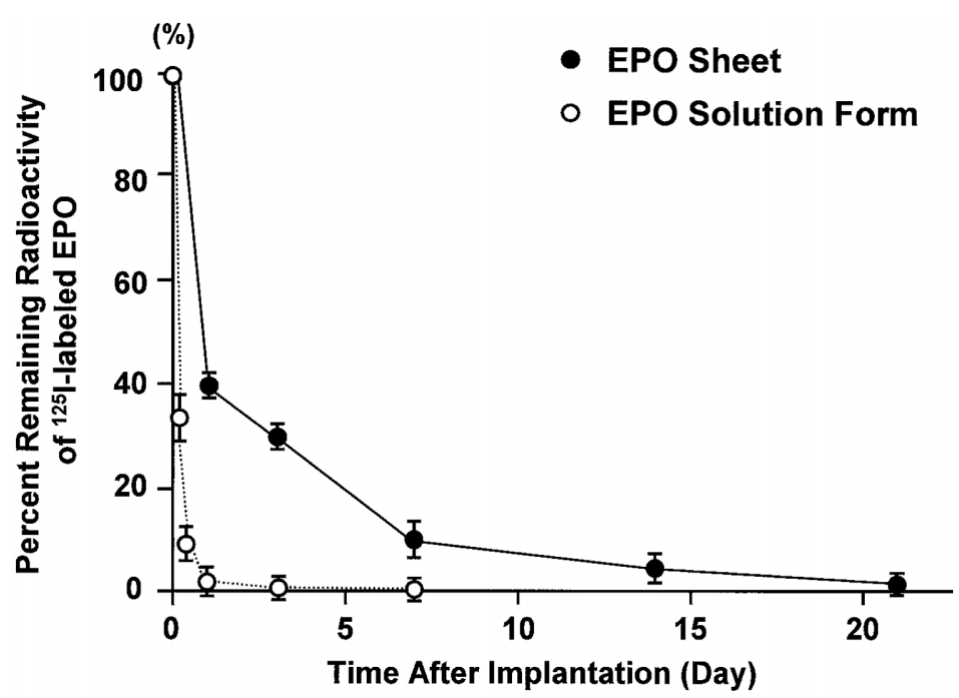

Fig 1. Time course of residual radioactivity at the site of injection with EPO solution and implantation with EPO incorporating gelatin hydrogel sheets. Error bars show SEM. The number of rats for each time point was 3. EPO, erythropoietin. viously described process 21,22 Sheets were freeze-dried and cut in a rectangular shape for impregnation with phosphate buffered saline containing EPO $(3,000 \mathrm{U}$ in $0.5 \mathrm{ml}$; Sigma, Tokyo, Japan) at room temperature for $3 \mathrm{~h}$. The prepared EPO-incorporating gelatin hydrogel sheets were used immediately after preparation.

\section{In Vivo Evaluation of EPO Release and Gelatin Hydrogel Sheet Degradation}

Gelatin hydrogels incorporating ${ }^{125}$ I-labeled EPO were implanted subcutaneously into the dorsum of the mice, and $100 \mu \mathrm{l}$ of subcutaneously injected aqueous solution of ${ }^{125} \mathrm{I}-$ labeled EPO was used as a control. The mice were killed at various intervals, and the skin around the EPO-implant or injection site was cut into strips. The fascia was thoroughly wiped with filter paper and the remaining radioactivity of the gelatin hydrogel, excised skin, and filter paper was measured on a gamma counter (ARC-301B; Aloka Co Ltd, Tokyo, Japan) to evaluate the time profile of in vivo degradation of the gelatin hydrogels.

\section{Chronic MI Model}

MI was created in rats weighing $250-290 \mathrm{~g}$ by ligating the proximal left anterior descending (LAD) coronary artery through a left thoracotomy, as described in our previous reports ${ }^{23-27}$ Four weeks after the LAD ligation, infarction size and cardiac function were evaluated by means of echocardiography and cardiac catheterization, as described below.

Experimental Groups Four weeks after the coronary artery ligation, 50 rats with moderate-sized MI were assigned to 5 groups (each group, $n=10$ ). Group I, which had a saline-incorporated gelatin hydrogel sheet, served as the controls, and groups 2-5 had gelatin hydrogel sheets incorporating $0.1 \mathrm{U}, 1 \mathrm{U}, 10 \mathrm{U}$ and $100 \mathrm{U}$ of EPO, respectively. In each group, the rectangular gelatin hydrogel sheet was stabilized to the LV wall with 6-0 polypropylene sutures to cover the area of MI completely. 3

\section{Echocardiography}

Echocardiography assessment was performed according to the method previously described ${ }^{23-27}$ In brief, LV dimension and function were assessed just before treatment, and followed up 2 and 4 weeks later. Images were recorded using a $10-12 \mathrm{MHz}$ phased array transducer (Model
21380A with HP SONOS 5500 imaging system, Agilent Technologies, Andover, MA, USA). LV end-diastolic and end-systolic dimensions (LVDd and LVDs, respectively) were measured with M-mode tracings from the short-axis view of the LV at the papillary muscle level. Fractional area change (FAC) and the percentage of akinetic endocardial length to the whole LV endocardial circumference (AL) were also calculated from the same short-axis view. All measurements were performed in a blind fashion according to the American Society of Echocardiology, and averaged over 3 consecutive cardiac cycles.

\section{Cardiac Catheterization}

After the final echocardiographic evaluation, the rats underwent cardiac catheterization for more precise assessment of global LV function as described previously?23,25 In brief, under general anesthesia, a $2 \mathrm{~F}$ micromanometertipped catheter (Millar Instruments Inc, Houston, TX, USA) was inserted via the right carotid artery into the LV, and a $3 \mathrm{~F}$ occlusion balloon catheter through the right femoral vein into the inferior vena cava. LV pressure and its first time-derivative $(\mathrm{dp} / \mathrm{dt})$ were continuously monitored using a multiple recording system. The LV end-systolic volume was calculated from the M-mode echocardiograms by the cube formula. During the inferior vena cava occlusion with the balloon, pressure waveforms and M-mode tracings were simultaneously recorded, and the end-systolic elastance (Ees) and the time constant of isovolumic relaxation (Tau) were derived from the recorded data. In calculating Ees, the end-systolic pressure-volume points obtained from echocardiography and cardiac catheterization were subjected to least squared linear regression. All data were acquired under stable conditions.

\section{Analysis of Vascular Density}

After the final hemodynamic assessment, all rats were killed for the histological study. The specimens were paraffin-embedded, and the whole hearts were sectioned in $3 \mu \mathrm{m}$ thickness at $100 \mu \mathrm{m}$ intervals along the short axis. In the peri-MI area, the number of vessels was counted in each heart using immunohistochemistry for von Willebrand factor (U0034; Dako A/S, Glostrup, Denmark). The vessels per $1 \mathrm{~mm}^{2}$ in the pertinent zone were counted in 3 randomly chosen fields per slide in a blind manner and averaged for statistical analysis. 
Table 1 Echocardiographic Data

\begin{tabular}{|c|c|c|c|c|c|}
\hline & \multirow{2}{*}{ Control } & \multicolumn{4}{|c|}{$E P O$} \\
\hline & & $0.1 U$ & $1 U$ & $10 \mathrm{U}$ & $100 \mathrm{U}$ \\
\hline \multicolumn{6}{|c|}{$L V D d(\mathrm{~cm})$} \\
\hline Before & $1.06 \pm 0.06$ & $1.09 \pm 0.06$ & $1.07 \pm 0.05$ & $1.08 \pm 0.07$ & $1.07 \pm 0.08$ \\
\hline After & $1.12 \pm 0.02 *$ & $1.12 \pm 0.04$ & $1.01 \pm 0.02 *,+, \pm, \mathscr{I}$ & $1.04 \pm 0.03^{\dagger, \ddagger, \pi}$ & $1.10 \pm 0.02$ \\
\hline \multicolumn{6}{|c|}{ LVDs (cm) } \\
\hline Before & $0.87 \pm 0.07$ & $0.88 \pm 0.06$ & $0.86 \pm 0.06$ & $0.87 \pm 0.09$ & $0.86 \pm 0.05$ \\
\hline After & $0.94 \pm 0.02 *$ & $0.94 \pm 0.04 *$ & $0.81 \pm 0.02 *,+,+\pi$ & $0.84 \pm 0.04^{\dagger, \dot{t}, \mathscr{I}}$ & $0.88 \pm 0.02$ \\
\hline \multicolumn{6}{|l|}{$F A C(\%)$} \\
\hline Before & $33.7 \pm 2.6$ & $34.0 \pm 4.0$ & $33.8 \pm 4.3$ & $33.4 \pm 3.9$ & $33.2 \pm 2.3$ \\
\hline After & $25.9 \pm 0.9 *$ & $29.0 \pm 2.1 *$ & $39.0 \pm 1.5^{*, t, t, \pi}$ & $35.9 \pm 2.1^{\dagger, \pm, \mathscr{H}}$ & $28.3 \pm 1.2$ \\
\hline \multicolumn{6}{|l|}{$A L(\%)$} \\
\hline Before & $25.7 \pm 3.3$ & $27.0 \pm 2.5$ & $25.3 \pm 3.0$ & $26.6 \pm 3.1$ & $26.1 \pm 2.5$ \\
\hline After & $30.9 \pm 1.5 *$ & $28.6 \pm 2.3$ & $21.0 \pm 0.6^{*,+, \dot{\ddagger}, \mathscr{I}}$ & $23.6 \pm 3.1 * t,+, \pi$ & $27.1 \pm 1.8$ \\
\hline
\end{tabular}

Values are mean $\pm S E M$.

EPO, erythropoietin; LVDd, left ventricular end-diastolic dimension; LVDs, left ventricular end-systolic dimension; FAC, fractional area change; $A L$, percentage of akinetic endocardial length to the whole left ventricular endocardial circumference.

${ }^{*} p<0.05$ vs values before treatment in the same group. ${ }^{\dagger} p<0.05$ vs control; ${ }^{\ddagger} p<0.05$ vs EPO $0.1 \mathrm{U} ;{ }^{\mathbb{I}} p<0.05$ vs EPO $100 \mathrm{U}$.

Ees $(\mathrm{mmHg} / \mathrm{\mu l})$

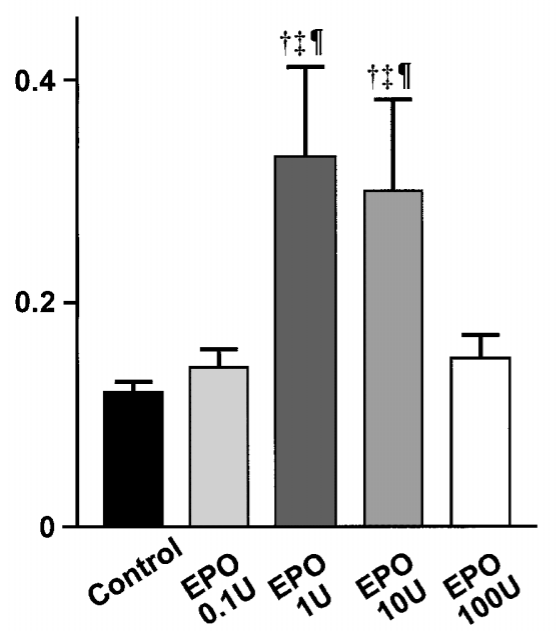

Tau (ms)

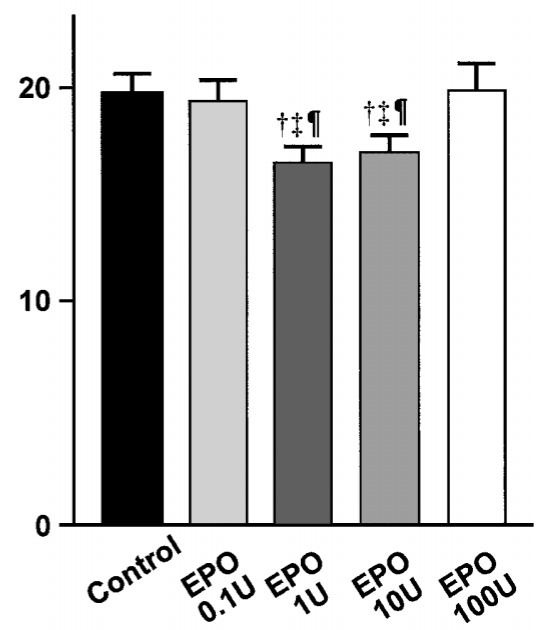

Fig 2. Data on cardiac catheterization. Error bars show SEM. Ees, end-systolic elastance; Tau, time constant of isovolumic relaxation; EPO, erythropoietin. ${ }^{\dagger} \mathrm{p}<0.05$ vs control, $\stackrel{\ddagger}{\mathrm{p}}<$ 0.05 vs EPO $0.1 \mathrm{U}$, I $\mathrm{p}<0.05$ vs EPO $100 \mathrm{U}$.

\section{Measurement of Red Blood Cells (RBC)}

Blood samples were obtained from a peripheral tail vein of sedated rats at 0,2 , and 4 weeks after the treatment. Samples were analyzed using a Celltac (Model MEK-6358, NIHON KODEN, Japan).

\section{Data Analysis}

All data are expressed as the mean \pm standard error of the mean. Comparisons of echocardiographic data and the number of RBC among the groups were performed by 2-way repeated measures analysis of variance (ANOVA) including time, group, and group-by-time interaction terms. Comparisons of cardiac catheterization data and vascular density among the groups were conducted by one-way factorial ANOVA. All statistical analyses were performed using computer software (StatView for Windows version 5.0, SAS Institute Inc, Cary, NC, USA). A p-value $<0.05$ was considered statistically significant.

\section{Results}

Both the mortality after coronary artery ligation and the size of the MI were similar to our previous reports. 26,27

\section{EPO Concentration by Gelatin Sheet Treatment}

Fig 1 depicts the time course of remaining radioactivity of 125 I-labeled EPO after subcutaneous injection of EPO solution or subcutaneous implantation of gelatin hydrogels sheet incorporating EPO. More than $95 \%$ of the EPO injected as solution was cleared from the injected site within 1 day, whereas there was a prolonged release of EPO from the hydrogel at the site of implantation.

\section{Echocardiography}

There were no significant differences among the 5 groups in any data for cardiac function at 4 weeks after coronary artery ligation (Table 1). In the analyses of LVDd and LVDs, group and time effects and group-by-time interactions were strongly recognized. At 4 weeks after each treatment, LVDd in the groups with EPO $1 \mathrm{U}$ and $10 \mathrm{U}$ was significantly smaller than in the control group and the groups with EPO $0.1 \mathrm{U}$ and $100 \mathrm{U}$. The groups with EPO $1 \mathrm{U}$ and $10 \mathrm{U}$ had significantly smaller LVDs than the control group. In addition, in groups with EPO $1 \mathrm{U}$ and $10 \mathrm{U}$, FAC was significantly larger and AL was significantly smaller than in the control group and groups with EPO 0.1 U and 100 U. 

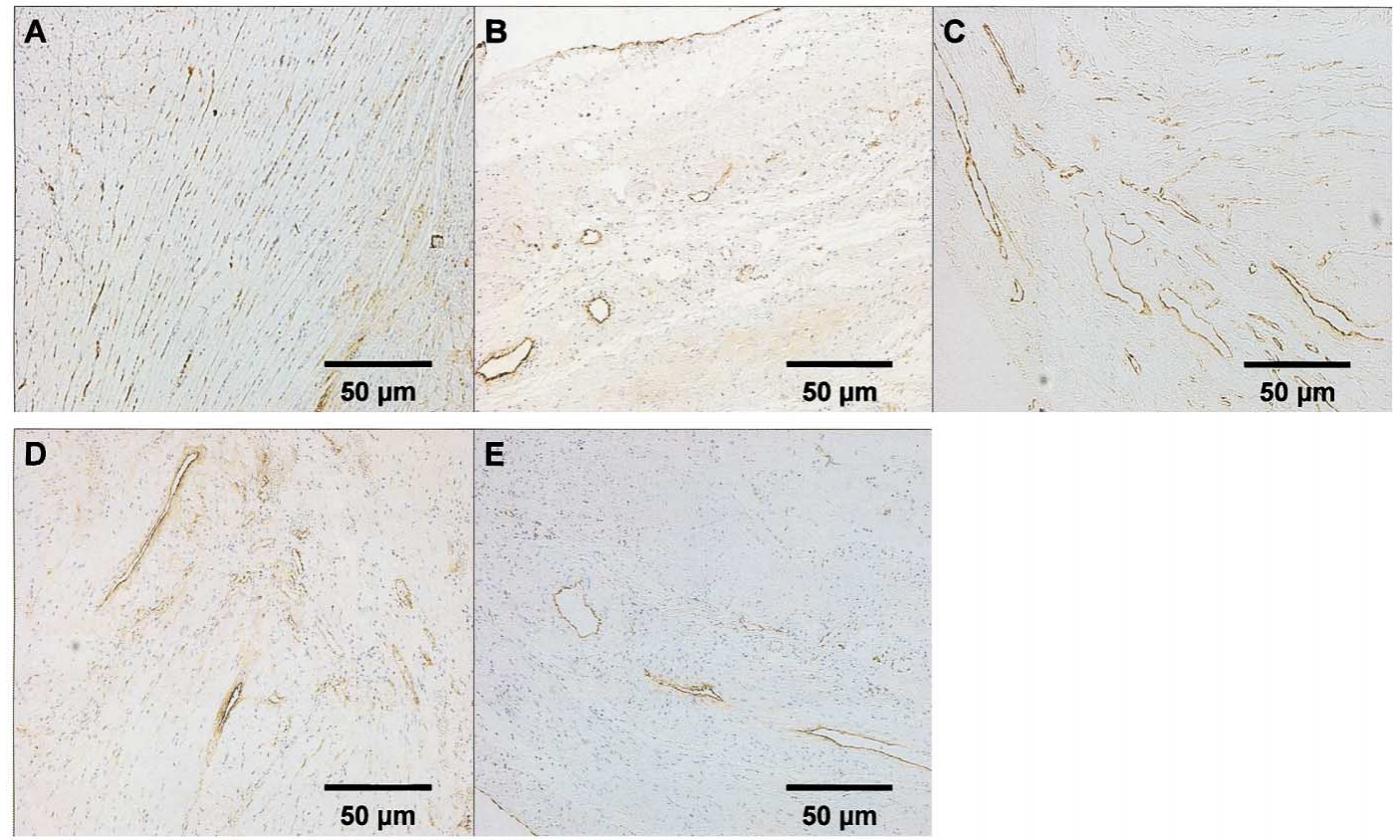

Fig 3. Immunohistochemistry for von Willebrand factor (brown, $\times 100$ ). (A-E) representative images of the peri-MI area from control, erythropoietin $0.1 \mathrm{U}, 1 \mathrm{U}, 10 \mathrm{U}$, and $100 \mathrm{U}$ groups, respectively.

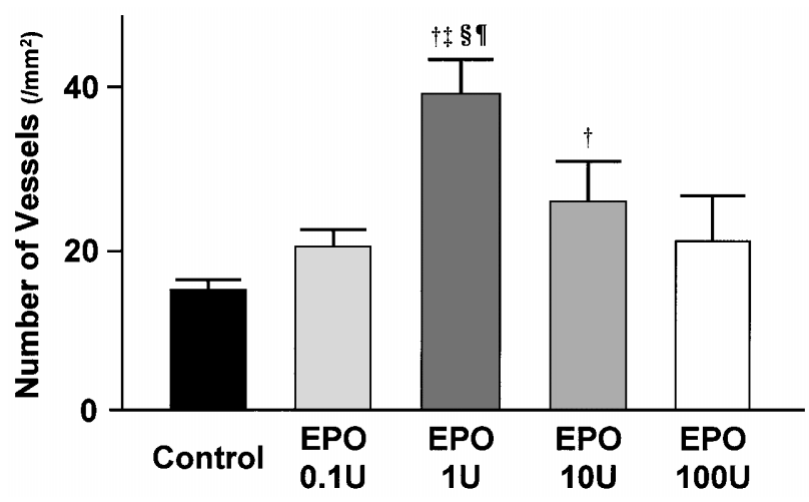

Fig 4. Vascular density in the peri-MI area. EPO, erythropoietin. $\dagger \mathrm{p}<0.05$ vs control, $\ddagger_{\mathrm{p}}<0.05$ vs EPO $0.1 \mathrm{U}, \S_{\mathrm{p}}<0.05$ vs EPO $10 \mathrm{U}$, $\mathbb{T}_{\mathrm{p}}<0.05$ vs EPO $100 \mathrm{U}$.

\section{Cardiac Catheterization}

One-way factorial ANOVA showed a high group effect in both Ees and Tau (Fig 2). The Ees was the highest in the group with EPO $1 \mathrm{U}$ (control: $0.12 \pm 0.01$, EPO $0.1 \mathrm{U}$ : 0.14 \pm 0.02 , EPO $1 \mathrm{U}: 0.33 \pm 0.08$, EPO 10 U: 0.30 \pm 0.08 , EPO $100 \mathrm{U}: 0.15 \pm 0.02 \mathrm{mmHg} \mu \mathrm{l}$, respectively). Also, the Tau was the lowest in the group with EPO $1 \mathrm{U}$ among them (control: 19.7 \pm 0.9 , EPO 0.1 U: 19.3 \pm 1.0 , EPO $1 \mathrm{U}: 16.6 \pm 0.6$, EPO 10U: $16.9 \pm 0.8$, EPO $100 \mathrm{U}: 19.7 \pm 1.3 \mathrm{~ms})$.

\section{Vascular Density}

Representative images are shown in Fig 3. The vascular density in the peri-MI area was highest in the group with EPO $1 \mathrm{U}$ (control, EPO 0.1 U, $1 \mathrm{U}, 10 \mathrm{U}, 100 \mathrm{U}: 13.68 \pm 2.49$, $21.08 \pm 2.75,37.97 \pm 4.19,24.42 \pm 6.07,21.54 \pm 4.68 / \mathrm{mm}^{2}$, respectively). The vascular density in the group with EPO $10 \mathrm{U}$ was significantly higher than in the control group $\left(24.42 \pm 6.07\right.$ vs $\left.13.68 \pm 2.49 / \mathrm{mm}^{2} ; \mathrm{p}<0.05\right)$ (Fig 4$)$.

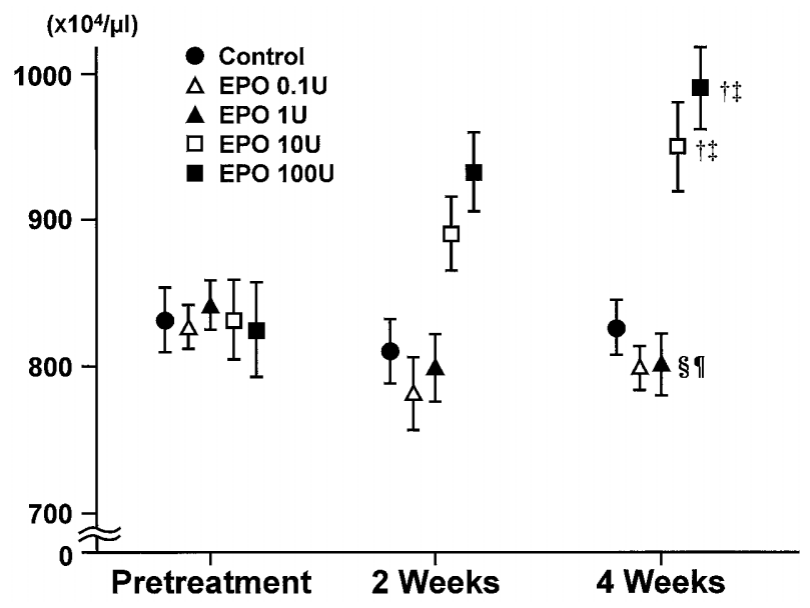

Fig 5. Red blood cell count. Error bars show SEM. EPO, erythropoietin. ${ }^{\dagger} \mathrm{p}<0.05$ vs control, ${ }^{\star} \mathrm{p}<0.05$ vs EPO $0.1 \mathrm{U},{ }^{\S} \mathrm{p}<0.05$ vs EPO $10 \mathrm{U}$, Ip $<0.05$ vs EPO $100 \mathrm{U}$.

\section{RBC Analysis}

In the groups with EPO $10 \mathrm{U}$ and $100 \mathrm{U}$, the number of $\mathrm{RBC}$ at 4 weeks after treatment was significantly higher than in the control group. The number of $\mathrm{RBC}$ in the groups with EPO 0.1 U and $1 \mathrm{U}$ was comparable with the control group (Fig 5) (control, EPO 0.1 U, $1 \mathrm{U}, 10 \mathrm{U}, 100 \mathrm{U}$; pretreatment baseline: $832 \pm 22,827 \pm 15,842 \pm 17,832 \pm 27$, $825 \pm 32 \times 10^{4} \mu 1$; 4 weeks: $826 \pm 19,798 \pm 15,801 \pm 21,949 \pm$ $\left.30,989 \pm 28 \times 10^{4} \mu \mathrm{l}\right)$.

\section{Discussion}

The salient findings of this study are as follows: (1) the SR system with EPO enabled release of EPO from a gelatin hydrogel sheet over a period greater than 3 weeks, and (2) the most relevant dose of EPO incorporated in the sheet for 
improving LV function without inducing polycythemia was $1 \mathrm{U}$ in the rat chronic MI model.

It is pertinent to comment on reasons why we used SR EPO sheets rather than gelatin hydrogel microspheres incorporating EPO. In our earlier studies, gelatin hydrogel microsphere ${ }^{28-31}$ and sheets ${ }^{6,7}$ were used as a carrier of SR bFGF. For the purpose of healing of devascularized sternum, we used gelatin sheets incorporating bFGF, for anatomical reasons, 6,7 but in the case of $\mathrm{MI}$, we injected a solution of $100 \mathrm{l}$ containing gelatin bFGF microspheres into several sites of the border zones of MI scar tissue ${ }^{28,29}$ There are several limitations to that therapeutic approach. First, intramyocardial injection itself may injure the myocardium. Second, the thin scar tissue may limit the appropriate space for microsphere retention. Finally, it is difficult to determine the local concentration of released bFGF in situ. Epicardial application of gelatin sheets may overcome these disadvantages and in fact, gelatin hydrogel sheets incorporating other angiographic growth factors are being used in experimental settings ${ }^{24,25}$ An epicardial application of a bone-marrow-cell-seeded biodegradable polymeric scaffold is reported to be useful for enhancing angiogenesis and improving myocardial function in the infarcted heart 32

It is tempting to speculate about how EPO suppresses LV remodeling and ameliorates LV contractility and relaxation after MI. There are 3 possible mechanisms responsible for the reduction of functional decline after MI (ie, progression in the LV observed in rats of the control group in the present study). First of all, augmented angiogenesis might contribute to functional recovery after MI. In the present study, the vascular density in the peri-MI area was positively correlated with FAC and Ees, and negatively correlated with AL and Tau. Although a good correlation does not necessarily indicate a cause-effect relationship, it is conceivable that EPO-induced angiogenesis might ameliorate LV functional recovery. Our speculation is supported by the fact that EPO accelerates naturally occurring capillary overgrowth as powerfully as vascular endothelial growth factor ${ }^{33} \mathrm{Sec}-$ ond, favorable effects with EPO may result from its ability to reduce apoptotic cell death. It has been demonstrated that the number of apoptotic cardiomyocytes in the infarct area was decreased significantly by EPO treatment in a rat AMI model ${ }^{14,15,19}$ although EPO administration did not affect the apoptosis of cardiomyocytes in a rat chronic MI model 18 This discrepancy may be explained by the fact that apoptotic cell death tapers with the progression of pathological changes of MI 34 In fact, in the present study reported here, approximately $0.1 \%$ nuclei of cardiomyocytes were TUNEL positive in the area at risk of untreated hearts at 8 weeks after coronary artery ligation. Thus, the contribution toward prevention of apoptosis by EPO treatment may be minimal, if any, in our experimental model. Another beneficial effect of EPO treatment may be its anti-inflammatory effects via attenuation of pro-inflammatory cytokine production 35 However, it is difficult to specify these favorable effects to EPO, because prevention of $\mathrm{LV}$ remodeling by EPO treatment may result in subsidence of the inflammatory response to myocardial ischemic injury.

Previous investigators have attempted to find the optimal EPO dose for improving LV function without inducing polycythemia in the chronic MI model. van der Meer et al produced LV functional improvement with intraperitoneal EPO administration at a dose of $8,000 \mathrm{U} / \mathrm{kg}$; 18 however, significant polycythemia inevitably occurred. In contrast, a single intravenous injection of $1,000 \mathrm{U} / \mathrm{kg}$ EPO did not improve LV function ${ }^{36}$ Thus, it is difficult to determine the therapeutically useful EPO dose in the chronic MI model. Our therapeutic approach with a SR drug delivery system overcame these problems of EPO treatment. Indeed, when a $1 \mathrm{U}$ EPO gelatin sheet was applied, the plasma EPO concentration was augmented by less than $0.5 \%$, which is negligible in comparison with the more than 100-fold increase in the case of a single intraperitoneal EPO injection at a dose of $8,000 \mathrm{U} / \mathrm{kg} 18$ Thus, the clinical application of EPO treatment for chronic MI is promising with the use of this newly developed drug delivery system.

It deserves some comment why the $100 \mathrm{U}$ EPO did not improve the endpoints. As shown in Fig 2, myocardial function was most improved with $1 \mathrm{U}$ EPO treatment, and it showed a gradual deterioration with increasing doses of EPO. The dose-independency may be, at least in part, explained by the fact that polycythemia associated with $10 \mathrm{U}$ and $100 \mathrm{U}$ EPO treatment may disturb the microcirculation in the infarcted area because of the high blood viscosity. Further studies are necessary to elucidate the paradoxical dose-dependency with EPO treatment.

\section{Study Limitations}

For gelatin hydrogel sheet application, re-opening the chest is inevitable at 4 weeks after AMI, which is more invasive than a single intravenous injection of EPO. The disadvantage may be counterbalanced by combined coronary artery bypass grafting surgery. Another limitation to the clinical application of the new treatment strategy is the relatively narrow window of optimal doses with EPO. To overcome these drawbacks, clinical studies are needed to determine the optimal dose of EPO in humans.

In future, we need to conduct double-blind, randomized controlled clinical trials to establish the effects of SR EPO treatment on surrogate markers such as LV ejection fraction, myocardial perfusion and exercise tolerance in patients with ungraftable viable myocardium.

In conclusion, application of gelatin hydrogel sheets incorporating $1 \mathrm{U}$ EPO successfully reversed LV remodeling without inducing polycythemia in the rat chronic MI model. This new treatment strategy to treat ischemic cardiomyopathy will be realized in the clinical setting in the near future.

\section{Acknowledgments}

We would like to express our sincere gratitude to Mrs Fumiyo Kataoka for her expert technical assistance, and acknowledge the meticulous assistance of Miss Yukiko Okumura during the preparation of this manuscript.

\section{References}

1. Simons M, Annex BH, Laham RJ, Kleiman N, Henry T, Dauerman $\mathrm{H}$, et al. Pharmacological treatment of coronary artery disease with recombinant fibroblast growth factor-2: Double-blind, randomized, controlled clinical trial. Circulation 2002; 105: 788-793.

2. Henry TD, Annex BH, McKendall GR, Azrin MA, Lopez JJ, Giordano FJ, et al. The VIVA trial: Vascular endothelial growth factor in Ischemia for Vascular Angiogenesis. Circulation 2003; 107: $1359-1365$.

3. Laham RJ, Sellke FW, Edelman ER, Pearlman JD, Ware JA, Brown $\mathrm{DL}$, et al. Local perivascular delivery of basic fibroblast growth factor in patients undergoing coronary bypass surgery: Results of a phase I randomized, double-blind, placebo-controlled trial. Circulation 1999; 100: $1865-1871$.

4. Losordo DW, Vale PR, Hendel RC, Milliken CE, Fortuin FD, Cummings N, et al. Phase $1 / 2$ placebo-controlled, double-blind, doseescalating trial of myocardial vascular endothelial growth factor 2 gene transfer by catheter delivery in patients with chronic myocardial ischemia. Circulation 2002; 105: 2012-2018.

5. Grines CL, Watkins MW, Mahmarian JJ, Iskandrian AE, Rade JJ, 
Marrott P, et al. A randomized, double-blind, placebo-controlled trial of Ad5FGF-4 gene therapy and its effect on myocardial perfusion in patients with stable angina. J Am Coll Cardiol 2003; 42: 1339_ 1347.

6. Iwakura A, Tabata Y, Miyao M, Ozeki M, Tamura N, Ikai A, et al. Novel method to enhance sternal healing after harvesting bilateral internal thoracic arteries with use of basic fibroblast growth factor. Circulation 2000; 102(Suppl III): IIII-307-III-311.

7. Iwakura A, Tabata Y, Tamura N, Doi K, Nishimura K, Nakamura T, et al. Gelatin sheet incorporating basic fibroblast growth factor enhances healing of devascularized sternum in diabetic rats. Circulation 2001; 104(Suppl I): I-325-I-329.

8. Brines ML, Ghezzi P, Keenan S, Agnello D, de Lanerolle NC, Cerami $\mathrm{C}$, et al. Erythropoietin crosses the blood-brain barrier to protect against experimental brain injury. Proc Natl Acad Sci USA 2000; 97: 10526-10531.

9. Kaptanoglu E, Solaroglu I, Okutan O, Surucu HS, Akbiyik F, Beskonakli E. Erythropoietin exerts neuroprotection after acute spinal cord injury in rats: Effect on lipid peroxidation and early ultrastructural findings. Neurosurg Rev 2004; 27: 113-120.

10. Junk AK, Mammis A, Savitz SI, Singh M, Roth S, Malhotra S, et al. Erythropoietin administration protects retinal neurons from acute ischemia-reperfusion injury. Proc Natl Acad Sci USA 2002; 99: 10659-10664.

11. Grimm C, Wenzel A, Groszer M, Mayser H, Seeliger M, Samardzija $\mathrm{M}$, et al. HIF-1-induced erythropoietin in the hypoxic retina protects against light-induced retinal degeneration. Nat Med 2002; 8: 718 724.

12. Vesey DA, Cheung C, Pat B, Endre Z, Gobe G, Johnson DW. Erythropoietin protects against ischaemic acute renal injury. Nephrol Dial Transpl 2004; 19: 348-355.

13. Calvillo L, Latini R, Kajstura J, Leri A, Anversa P, Ghezzi P, et al. Recombinant human erythropoietin protects the myocardium from ischemia-reperfusion injury and promotes beneficial remodeling. Proc Natl Acad Sci USA 2003; 100: 4802-4806.

14. Moon C, Krawczyk M, Ahn D, Ahmet I, Paik D, Lakatta EG, et al. Erythropoietin reduces myocardial infarction and left ventricular functional decline after coronary artery ligation in rats. Proc Natl Acad Sci USA 2003; 100: 11612-11617.

15. Parsa CJ, Matsumoto A, Kim J, Riel RU, Pascal LS, Walton GB, et al. A novel protective effect of erythropoietin in the infarcted heart. J Clin Invest 2003; 112: 999-1007.

16. Parsa CJ, Kim J, Riel RU, Pascal LS, Thompson RB, Petrofski JA, et al. Cardioprotective effects of erythropoietin in the reperfused ischemic heart: A potential role for cardiac fibroblasts. J Biol Chem 2004; 279: 20655-20662.

17. Cai Z, Manalo DJ, Wei G, Rodriguez ER, Fox-Talbot K, Lu H, et al. Hearts from rodents exposed to intermittent hypoxia or erythropoietin are protected against ischemia-reperfusion injury. Circulation 2003; 108: $79-85$.

18. van der Meer P, Lipsic E, Henning RH, Boddeus K, van der Velden $\mathrm{J}$, Voors AA, et al. Erythropoietin induces neovascularization and improves cardiac function in rats with heart failure after myocardial infarction. J Am Coll Cardiol 2005; 46: 125-133.

19. Moon C, Krawczyk M, Paik D, Coleman T, Brines M, Juhaszova M, et al. Erythropoietin, modified to not stimulate red blood cell production, retains its cardioprotective properties. J Pharmacol Exp Ther 2006; 316: 999-1005.

20. Bullard AJ, Yellon DM. Chronic erythropoietin treatment limits infarct-size in the myocardium in vitro. Cardiovasc Drug Ther 2005; 19: $333-336$

21. Tabata Y, Hijikata S, Ikada Y. Enhanced vascularization and tissue granulation by basic fibroblast growth factor impregnated in gelatin hydrogels. J Control Release 1994; 31: 189-199.

22. Fukunaka Y, Iwanaga K, Morimoto K, Kakemi M, Tabata Y. Controlled release of plasmid DNA from cationized gelatin hydrogels based on hydrogel degradation. J Control Release 2002; 80: $333-$ 343.

23. Sakakibara Y, Nishimura K, Tambara K, Yamamoto M, Lu F, Tabata $\mathrm{Y}$, et al. Prevascularization with gelatin microspheres containing basic fibroblast growth factor enhances the benefits of cardiomyocyte transplantation. J Thorac Cardiovasc Surg 2002; 124: 50-56.

24. Sakaguchi G, Tambara K, Sakakibara Y, Ozeki M, Yamamoto M, Premaratne G, et al. Control-released hepatocyte growth factor prevents the progression of heart failure in stroke-prone spontaneously hypertensive rats. Ann Thorac Surg 2005; 79: 1627-1634.

25. Tambara K, Premaratne GU, Sakaguchi G, Kanemitsu N, Lin X, Nakajima $\mathrm{H}$, et al. Administration of control-released hepatocyte growth factor enhances the efficacy of skeletal myoblast transplantation in rat infarcted hearts by greatly increasing both quantity and quality of the graft. Circulation 2005; 112(Suppl II): II-129-II-134.

26. Sakakibara Y, Tambara K, Lu F, Nishina T, Sakaguchi G, Nagaya N, et al. Combined procedure of surgical repair and cell transplantation for left ventricular aneurysm: An experimental study. Circulation 2002; 106(Suppl I): I-193-I-197.

27. Tambara K, Sakakibara Y, Sakaguchi G, Lu F, Premaratne GU, Lin $\mathrm{X}$, et al. Transplanted skeletal myoblasts can fully replace the infarcted myocardium when they survive in the host in large numbers. Circulation 2003; 108(Suppl II): II-259-II-263.

28. Yamamoto T, Suto N, Okubo T, Mikuniya A, Hanada H, Yagihashi $\mathrm{S}$, et al. Intramyocardial delivery of basic fibroblast growth factorimpregnated gelatin hydrogel microspheres enhances collateral circulation to infarcted canine myocardium. Jpn Circ J 2001; 65: $439-444$.

29. Iwakura A, Fujita M, Kataoka K, Tambara K, Sakakibara Y, Komeda $\mathrm{M}$, et al. Intramyocardial sustained delivery of basic fibroblast growth factor improves angiogenesis and ventricular function in a rat infarct model. Heart Vessels 2003; 18: 93-99.

30. Shao ZQ, Takaji K, Katayama Y, Kunitomo R, Sakaguchi H, Lai ZF, et al. Effects of intramyocardial administration of slow-release basic fibroblast growth factor on angiogenesis and ventricular remodeling in a rat infarct model. Circ J 2006; 70: 471-477.

31. Hirose K, Fujita M, Marui A, Arai Y, Sakaguchi H, Huang Y, et al. Combined treatment of sustained-release basic fibroblast growth factor and sarpogrelate enhances collateral blood flow effectively in rabbit hindlimb ischemia. Circ J 2006; 70: 1190-1194.

32. Fukuhara S, Tomita S, Nakatani T, Fujisato T, Ohtsu Y, Ishida M, et al. Bone marrow cell-seeded biodegradable polymeric scaffold enhances angiogenesis and improves function of the infracted heart. Circ J 2005; 69: 850-857.

33. Jaquet K, Krause K, Tawakol-Khodai M, Geidel S, Kuck KH. Erythropoietin and VEGF exhibit equal angiogenic potential. Microvasc Res 2002; 64: 326-333.

34. Palojoki E, Saraste A, Eriksson A, Pulkki K, Kallajoki M, VoipioPulkki LM, et al. Cardiomyocyte apoptosis and ventricular remodeling after myocardial infarction in rats. Am J Physiol Heart Circ Physiol 2001; 280: 2726-2731.

35. Villa P, Bigini P, Mennini T, Agnello D, Laragione T, Cagnotto A, et al. Erythropoietin selectively attenuates cytokine production and inflammation in cerebral ischemia by targeting neuronal apoptosis. J Exp Med 2003; 198: 971-975.

36. Hirata A, Minamino T, Asanuma H, Fujita M, Wakeno M, Myoishi $\mathrm{M}$, et al. Erythropoietin enhances neovascularization of ischemic myocardium and improves left ventricular dysfunction after myocardial infarction in dogs. J Am Coll Cardiol 2006; 48: 176-184. 